\title{
Addressing Complex Public Problems Through Coalition-Based Approaches: Collective Impact and the CEP Competencies
}

Melanie Brown

Washington State University

Tami L. Moore

Oklahoma State University 


\title{
Addressing Complex Public Problems Through Coalition-Based Approaches: Collective Impact and the CEP Competencies
}

\author{
Melanie Brown \\ Washington State University \\ Tami L. Moore \\ Oklahoma State University
}

\begin{abstract}
The most intractable public problems can be resolved only with the engagement of broad-based cross-sector coalitions. On university campuses, interdisciplinary coalitions are formed in recognition that one discipline alone cannot address a systemic challenge. Collective impact (Kania \& Kramer, 2011, 2013) has emerged as a collaborative community-based approach to addressing entrenched, complex issues and may extrapolate well to community-campus engagement. This article explores the intersection of university and community approaches to addressing complex issues through coalition-based strategies, in particular the emerging role of community engagement professionals in leading change. Next-generation community engagement professionals play a key role in convening, facilitating, and leading campus-community coalitions to solve complex public problems. The preliminary competency model for community engagement professionals (Dostilio et al., 2017) includes cultivating the conditions for change as a core theme, including the convening of collaborative groups in the context of the interdisciplinary, cross-sector environment typical at the nexus of campuses and communities.
\end{abstract}

Keywords: anchor institutions, CEP competency model, collective impact

Public problems - social, economic, environmental - are becoming more acute because they are occurring in an interdependent, globalized world rather than in local, isolated communities, however small or large (Friedman, 2018). Furthermore, the traditional approach to public problem solving taught in graduate schools involves technical experts, who are removed from the actual problem, attempting to figure out what should be done and then enacting solutions through legislation, policy, or enforcement protocols. The result is policy-centered, rather than human-centered, design (McGuinness \& Slaughter, 2019) that may or may not be a realistic fit "on the ground." Despite the global nature of many 21 st-century challenges and the tendency toward expert-driven solutions, Thomas Friedman (2018) saw hope in the pragmatic, grassroots approach to problem solving emerging in communities across the United States under the auspices of "complex adaptive coalitions" (para. 3) of cross-sector groups.

Solutions developed by coalitions can be understood as social innovations that translate concepts from the business world to address public problems. Ultimately, in the context of a social innovation, the "benefit of the change accrues primarily to society as a whole rather than private individuals" (Phills, Deiglmeier, \& Miller, 2007, p. 36). Leaders in the public and social sectors often adopt this approach because it aligns well with the market-driven ideologies shaping the U.S. political landscape and is trickling into the world of not-for-profit entities and universities. Social innovations of this sort greatly resemble communityuniversity engagement efforts (Dostillio \& Perry, 2017), particularly in multi-sector coalitions, publicprivate partnerships, and social service networks organized to address intractable public problems such as those Friedman (2018) discussed. Universities are well positioned as partners in such efforts, providing resources, expertise, and sustainability (Cantor, Englot, \& Higgins, 2013; Garber \& Adams, 2017; Orphan, Solodukhin, \& Romero, 2018) often managed through the dedicated efforts of a recently acknowledged category of university administrators: community engagement professionals (CEPs; Dostilio, 2017b; Dostilio \& McReynolds, 2015; Dostilio \& Perry, 2017). 
CEPs and other professionals pursuing community engagement and social innovation have much to learn from one another's approaches to addressing complex social problems. To that end, the purpose of this article is to explore how a coalition-based social innovation for addressing complex problems through collective impact can inform the role and competencies of CEPs within the context of an anchor-institution philosophy. Collective impact is an example of a collaborative community-based approach developed by social innovation consultants and implemented in urban and rural areas around the United States to develop sustainable solutions to complex social problems (Kania \& Kramer, 2011, 2013).

\section{Coalition-Based Approaches to Addressing Complex Public Problems}

Individuals in different sectors or organizational environments align with their institutional mission and purpose in response to pressing social problems such as low educational attainment, environmental racism, and food insecurity. Typically, the responses have at least one characteristic in common: They are often grounded in a coalition-based approach to addressing complex public problems. University-based researchers and CEPs engage with placed-based participants in the communities they serve through scholarly activities such as community-engaged participatory research, service-learning, and communitycampus issue-based partnerships (Moore, 2014). Senior campus leaders at many institutions have explicitly committed to enacting an anchor-institution mission in recognition of their college's or university's role as a key economic and social actor in their city or region (Hodges \& Dubb, 2012). The politics and demands of university employment make community organizing approaches less well suited to university leadership or individual faculty, but university-based partners certainly do engage with local community organizing efforts focused on building power in order to effect community-driven change (Kegler et al., 2019). Social entrepreneurs launch funder collaboratives, public-private partnerships, multi-stakeholder initiatives, and social sector networks organized to synergize the work of a broad spectrum of organizations and entities around a particular issue (Kania \& Kramer, 2011). All of these coalition-based approaches to public problem solving show some promise for addressing the most pressing issues - and doing so in a more or less human-centered way. We note a move in the philanthropic foundation community that warrants the attention of CEPs and their partners: Major national funders of community-based work, including the Annie E. Casey Foundation, the Bill and Melinda Gates Foundation, the Robert Wood Johnson Foundation, the Kellogg Foundation (ORS Impact \& Spark, 2018), and others working at a regional level, such as the George Kaiser Family Foundation, commonly reference one particular social innovation-collective impact - as a preferred approach.

\section{Collective Impact}

Collective impact (CI), defined as "the commitment of a group of important actors from different sectors to a common agenda for solving a specific social problem" (Kania \& Kramer, 2011, p. 36), represents one such coalition-based and socially innovative approach to public problem solving. To "produce true alignment [among coalition partners] and lead to powerful results" (Kania \& Kramer, 2011, p. 39), leaders of collective-impact initiatives must ensure five conditions of success. All members of the collaborative should pursue a common agenda that reflects agreed upon goals for measurable change. The partners develop shared measurement, or metrics for evaluation, to ensure that all parties are not only working toward these common goals but also measuring and reporting results of their interventions/actions in the same terms. Organizations engage in mutually reinforcing activities, all aimed at making measurable change in pursuit of the common goals. Continuous communication across the macro and micro levels of the coalition keep all actors aware of progress, changes, and issues to be addressed. Finally, a collaborative effort of this scale requires a backbone support organization to coordinate all aspects of the collective strategy, ensure appropriate and timely communication, and connect individual organizations with each other and to necessary resources. Kania and Kramer (2011) expanded on this final condition, making the case for both administrative support and adaptive leadership provided by the backbone support organization. The authors framed complex social problems, such as food insecurity or educational attainment, as adaptive problems, which "are complex, the answer is not known, and even if it were, no 
single entity has the resources or authority to bring about the necessary change" (Kania \& Kramer, 2011, p. 39; see also Heifetz, Kania, \& Kramer, 2004).

Principles of practice. In 2016, the Collective Impact Forum identified eight principles of practice. While not at the level of competency development, these principles are meant to guide practitioners in successfully implementing the collective action approach, providing strong parallels to consider as the CEP competency model is developed, especially with respect to the specific functions of convening, facilitating, and leading coalitions for change. The principles of practice for $\mathrm{CI}$ include the following:

a. Design and implement the initiative with a priority on equity, addressing the barriers to equitable outcomes for all populations.

b. Include community members in the collaborative to bring crucial perspectives and contributions rooted in lived experiences.

c. Recruit and co-create with cross-sector partners a diversity of actors required to create the systemlevel view.

d. Use data to continuously learn, adapt, and improve the collaborative problem-solving process of collective impact.

e. Cultivate leaders with unique system leadership skills to help participants understand the complexity and non-linearity of system-level change.

f. Focus on program and system strategies, including communication, coordination, practices, services, and policies.

g. Build a culture that fosters relationship, trust, and respect across participants in order to reach common understanding and shared goals.

h. Customize [approaches to one's practice] for the local context in order to deeply understand the problem as well as other efforts underway. (Collective Impact Forum, 2016)

The principles of practice conditions for success have been reinforced by a growing body of research that now includes the first national study of CI project sites. ORS Impact and the Spark Policy Institute (2018) examined 25 CI sites across the United States, guided by a central research question: "To what extent and under what conditions does the collective impact approach contribute to population level outcomes?" (p. 4). The findings affirmed the important role of backbone support and a common agenda: "Maturity in these two conditions was related to achieving a variety of outcomes" (p. 16). Further, results indicated that cross-sector leadership is instrumental in creating the system-level changes necessary to resolve complex challenges. The study also revealed that those organizations with a stated equity focus were perceived as more likely to achieve positive related outcomes. Implications of the study include the suggestion that, like enacting an anchor-institution mission, CI is a long-term, change-oriented proposition. Taking the time to lay a strong foundation and allow a coalition to mature is essential to its success.

Critique from the academy. We do not intend to suggest that collective impact should necessarily be adopted wholesale or without interrogation. Practitioner-scholars of community psychology and other community-based professions have noted many issues with CI and the literature espousing the practice. Tom Wolff (2016) is a leading voice in this effort, first offering his pointed critique identifying the "ten places where CI gets it wrong" (pp. 3-8), which fall into three principal categories: flawed assumptions about the transferability of business consulting principles to the practice of community development and public health; substandard scholarly merit of the literature espousing and reporting on CI initiatives; and the absence of an equity or social-justice orientation. The following year, Wolff co-authored a second piece with senior scholars whose work provides much of the theoretical and empirical foundation for communitybased practices in health fields and community development. Their assessment was straightforward: Collective impact is inherently flawed. First, Wolff and colleagues wrote, much of the CI literature circles back to a very limited sample of initiatives, ultimately offering no empirical evidence that the five conditions of success actually lead to broad-based change. Further, they argued, CI has largely neglected equity and justice in community building; instead, "coalitions and collaborations need a new way of engaging with communities that leads to transformative changes in power, equity, and justice" (Wolff et al., 2017, p. 2). It should be noted that the Collective Impact Forum published their principles of practice, 
outlined earlier, just about the same time Wolff and colleagues began theorizing a collaborating for equity and justice approach, and articulated their own principles for "challeng[ing] existing power structures by giving more power to those less enfranchised and threatening the power of current institutional systems and the community professionals who populate them" (Wolff et al., 2017, p. 10). Ultimately, they continued, "the key role of the collaborative needs to be building community leadership as opposed to being community leadership" (p. 10). Particularly those who are evaluating CI initiatives and supporting the work through the CI Forum seem to agree with Wolff and colleagues on this point, given the publication over time of tools and resources for CI initiatives to support community authority. The sticking point between these two intellectual camps - collective impact and collaborating for equity and justice - appears to be around the question of whether or not, and to what extent, "top-down efforts can be re-engineered to become grassroots efforts after the power has already been claimed by the powers that be" (Wolff et al., 2017, p. 11). Another way to frame the difference between the two approaches might be to delve further into the complexities of justice and/or equity as theoretical constructs, examining the different values and paradigmatic assumptions underlying $\mathrm{CI}$ and collaboration for equity and justice. Such a discussion is, however, beyond the scope of this article.

More to the point here is the work of White, Blatz, and Joseph (2019), who responded directly to the equity and justice critique, rejecting Wolff et al.'s (2017) conclusion that a CI initiative "that is mature in its ability to mobilize institutional resources cannot simultaneously accommodate community authority" (White et al., 2019, p. 51). The key word in White et al.'s response is mature; in their view, an immature initiative shuts out community voices. The authors were specific on this point:

Neither an institutional solution that shuts out community authority nor a community organizing model that does not effectively deploy institutional assets can realistically effect transformational change that produces equity and justice.... [C]ollective impact has always sought a third way. (p. 51)

Arguably, Kania, Hanleybrown, and Juster (2014) reflected this third way, calling on CI practitioners to think in a new way about who ought to be involved in CI initiatives, how people work together, and how progress happens.

We agree ${ }^{1}$ that Kania et al.'s (2014) call may be sufficient to address Wolff's (2016) concerns if, in fact, leaders of the CI initiative are not themselves oriented toward justice and equity, and infuse those explicit values in the collaboration process on all fronts. Strive Partnership, an early and often-cited CI exemplar (Kania \& Kramer, 2011, 2013), has itself matured regarding its members' intentional integration of community participation. White et al. (2019) wrote that "when White returned to lead Strive Partnership in 2017, he saw that despite impressive results, the regional work had shown some fragility for not having whole-heartedly embraced community authority and ingenuity in th[e] early days" (p. 50). Since 2017, they have transitioned to a "community-enhanced model," which "takes community authority into account by giving due weight to the spheres of influence on urban youth" (p. 50), who are the focus of their efforts. Byron White's role in this change - and his preexisting efforts toward equity and justice (White, 2010) should not be underestimated. This is not to say that no one else in the partnership shares his commitments; rather, he has an easily accessible record of published scholarship that can be cited to further support the attribution of the transition toward justice to the era specifically under his leadership (e.g., White, 2009, 2010, 2012, 2018).

Recalling the conditions for success outlined earlier, the premise of this article is that universities, and specifically units and individuals charged with facilitating community-university engagement, may be particularly well positioned to serve as backbone support organizations. In fact, the concept of a backbone support organization in the collective impact approach has a corollary in recent higher education literature. Anchor institutions are defined as stable and sustainable social institutions - universities, hospitals, religious and cultural institutions, public agencies, etc.- embedded in the community and integral to the fabric of that community - one part of a "complex matrix of interdependence" (Cantor et al., 2013) with responsibilities of institutional citizenship in that community. For a university adopting the frame and "civic agency" of an anchor institution, the opportunities for collaboration, partnership, and social impacts are 
multiplied. Learning environments are richer; engaged scholarship is expanded; and cross-sector, interdisciplinary teams take on new meaning and promise-becoming a "collaborative social infrastructure that can make change" (Cantor et al., 2013, p. 44). Accordingly, present efforts to articulate necessary skills and credential community engagement professionals and other boundary spanners in communities and universities ought to integrate skills and values relevant to CI into emerging competency models.

\section{Land-Grant Universities as Anchor Institutions}

Discussions of a higher education institution's responsibility to its community and how to enact these most appropriately are nothing new in popular or scholarly literature and conversation. The Morrill Act of 1862 established a system of land-grant colleges in all 50 states, each dedicated to advancing agricultural and mechanical knowledge and military training in the state. Charles Van Hise, president from 1903 to 1918 of the University of Wisconsin, a land-grant institution, articulated "The Wisconsin Idea": The role of the land-grant university is to improve the lives of the people of the state. ${ }^{2}$

Tracing this history is beyond the scope of this article; however, two significant and recent moments warrant mention as a historical backdrop. First, in 1999, the Kellogg Commission published an influential report on "the Engaged Institution," calling for a return to the mission of land-grant universities: to serve the public good. This report followed Ernest Boyer's (1990) classic work to redefine how knowledge is created in the academy, and later to include the role of community interaction in that work through his proposed scholarship of engagement (Boyer, 1996). Through these important efforts, national leaders simultaneously recognized university-based scholars and practitioners for their work embodying the civic purpose of higher education, and reminded them of the ongoing responsibility of representatives of landgrant universities to serve the ecosystem in which their institutions are situated (Bartha, Carney, Gale, Goodhue, \& Howard, 2014). University administrators thus began to redirect campus efforts from providing outreach and service to communities toward building collaboration and partnership with communities.

Woven through the history and tradition of the land-grant university is a strong interest in realizing the capacity of higher education institutions to act as engines for community and economic revitalization. Hodges and Dubb (2012) described colleges and universities pursuing an anchor-institution mission, acting upon their sense of responsibility as key social and economic institutions in particular geographic areas. Of the 10 institutions profiled by Hodges and Dubb, none is located outside a metropolitan area, giving the impression that anchor institutions - and the anchor-institution movement more broadly-represent an urban phenomenon. However, many land-grant institutions have a main campus or some significant presence in a rural area and thereby play a critical role as employer, educator, and economic asset. As presidents and faculty members have adapted to a renewed focus on their public purpose, coordinating offices identified with titles such as "Center for Civic Engagement" have emerged along with professionals dedicated to campus-community engagement.

\section{The Community Engagement Professional}

A new category of university administrators doing the work of engagement, community engagement professionals are dedicated to bridging campus and community for the greater good. CEPs formerly tasked with "primarily instrumental responsibilities" now regularly undertake and, in many instances, lead "complex, transformational, democratic, and change-oriented work" (Dostilio \& Perry, 2017, p. 34) They are tempered radicals, transformative leaders, and social entrepreneurs working for social justice, empowerment and capacity building, and innovative solutions to social problems (Dostilio, 2017a; Kowal, 2017). In acknowledgement of this complex work, CEPs are often referred to as boundary spanners (Weerts \& Sandmann, 2010; Williams, 2002), bridge builders (Bartha et al., 2014), and blended professionals (Whitchurch, 2009), all descriptors of a nuanced, developing, and emerging profession critical to the success of the community-university engagement enterprise prioritized by many higher education institutions. CEPs play a singular role in answering Post, Ward, Longo, and Saltmarsh's (2016) call for higher education to understand and enact engagement not as a product or an outcome, but as a sustainable process for building relationships with/in the community served by a particular institution. This process 
calls for specific activities, such as facilitating faculty research collaborations and student learning in and out of classrooms, as well as advancing the university within an anchor-institution philosophy. In short, CEPs inhabit all the spaces within and between campus and community (Post et al., 2016), convening and connecting people, ideas, and organizations (Bartha et al., 2014).

In the second-generation model of community engagement described by Post et al. (2016) and their various contributors, CEPs are frequently called on to engage multiple stakeholders in a generative process to address a community-identified problem. By necessity, CEPs are conveners, facilitators, and organizers who take a long view of the change-oriented goals of community engagement. They invite otherscommunity partners, students, faculty, university administrators - to invest with them in the short-term steps of a messy and meticulous process even as they work for long-term change. Once a collaborative group has convened, the CEP plays a critical role in establishing a base of knowledge, channeling the energy and direction of the group, and maximizing potential impacts by engaging with a broad network on and off campus to intersect with the group as needed. Transitioning from convening to facilitating, CEPs bring information and knowledge to the group, elicit group member knowledge, and empower the group to develop common purpose and to find a way forward together. CEPs engage the group in the work, the process, and the outcomes, keeping the group on track and intuitively "knowing" when, where, and how to step in and when to step back.

While much of the work of the CEP is generic facilitation, applicable in many situations, it also involves unique elements that have some precedent in the land-grant traditions of extension and continuing education professionals with deep community ties. Speaking to the role of continuing education professionals, Shannon and Wang (2010) stressed the importance of "establishing a reputation as a connector, providing unbiased space for different voices to be heard, and seeking overarching goals to build collaboration and encourage action" (p. 111). Many CEPs have been engaged in this convening and facilitation work for years, with groups of student leaders, faculty fellow cohorts, and advisory councils; the current push toward next-generation public engagement takes this work to another level with the opportunity and ability to convene and facilitate cross-sector, problem-solving coalitions.

Complex social issues - such as economic disparities; substance abuse; juvenile justice; environmental protection; and access to food, housing, education, and healthcare - can rarely be fit into any one disciplinary-specific (Moore \& Ward, 2010; Ward \& Moore, 2010). Rather, broad-based coalitions that include faculty, administrators, students working as colleagues, and representatives of community organizations pursuing solutions together are needed to make progress on resolving the complex public problems of the 21 st century (Longo, Kiesa, \& Battistoni, 2016). In such a process, the CEP acts as an expert who is "on tap, not on top" (Boyte \& Fretz, 2010), supporting a process focused on long-term outcomes in addition to short-term metrics, with an ultimate goal of building stronger communities and engaged institutions (Schmitz, 2012).

Bringing people together in community engagement is a necessary, fundamental part of the work of CEPs - necessary but not sufficient to achieve the desired social-change outcomes. Working across boundaries to motivate others to come to the table, invest in a process, and envision the outcomes takes all of the practical competencies as well as critical commitments to the vision of community engagement identified by Dostilio et al. (2017). Dostilio et al.'s model identifies six areas of competency for CEPs:

1. "Leading Change in Higher Education": reflecting a deep understanding of the role of higher education in a democracy;

2. "Institutionalizing Engagement": establishing community-campus engagement as integral to the academic mission;

3. "Facilitating Student Civic Learning and Development": optimizing student (and alumni) citizenship in a democracy;

4. "Administering Community Engagement Programs": effectively managing risks and resources to maximize impacts on campus and in the community;

5. "Facilitating Faculty Development and Support": articulating and advancing the scholarship of engagement; 
6. "Cultivating High-Quality Partnerships": creating diverse, responsible, and reliable networks for change.

Each of these areas contains suggested competencies in knowledge, skills, dispositions, and critical commitments that advance the work of campus-community engagement. The model is dense, with details that represent the vast scope of community engagement work, which many practitioners find "confounding" (Kowal, 2017). However, in the context of the current discussion, the question is whether or not the competency model for CEPs adequately identifies the competencies required to enact the broad-based coalitions necessary to address complex problems.

To explore this question, we explore an example of a coalition-based approach to change in eastern Washington initiated by CEPs. Typical of their cohort across the country, the CEPs of Washington State University's Center for Civic Engagement have played a long-term role in convening campus and community colleagues to address complex issues, with a specific focus on food insecurity in rural Washington and Idaho.

\section{The Complex Problem of Food Security in a Rural County: Expressing an Anchor-Institution Role and Sharing a Vision for Change}

The story of the Palouse Food Project presents an opportunity to not only explore the practice of community engagement professionals as conveners, but also consider the anchor-institution philosophy and collective impact as twin mechanisms aligned for social change. Doing so points to aspects of CI practice that may contribute positively to more traditional forms of community-university engagement practice, such as pursuing the land-grant mission and enacting a convening strategy as an anchor institution.

Pullman, Washington - home of Washington State University (WSU) and the annual Lentil Festival, featuring the world's largest pot of lentil chili-is a highly productive agricultural region located in the heart of what residents refer to as "the Pea and Lentil Capital of the World." Despite the verdant cropland, Whitman County (where Pullman is located) has the highest poverty rate in the state, exacerbated by the prevalence of food deserts. Community health in this area is supported by the presence of WSU, the state's land-grant university, with research and extension faculty committed to the continued well-being of their neighbors in surrounding small communities across the state.

Adequately addressing a multi-faceted issue such as food insecurity requires expertise in a variety of areas. In 2003, WSU's Community Service Learning Center (now the Center for Civic Engagement) convened a cross-sector group of community organizations and university representatives around a shared interest in advancing food security in Whitman County. Initially, this small group of campus and community stakeholders from disciplines including education, crop and soils/horticulture, history, and sociology, as well as representatives of the Community Action Center, Council on Aging and Human Services, Groundworks Institute, Pullman School District, and Koppel Community Gardens met at the local Congregational church to discuss strategies. What emerged was a campus-community-school collaboration to improve methods of linking food production and delivery systems through the strategic alignment of community and educational resources in an effort to better serve low-income populations in Whitman County. The goals of this early effort were three-fold: (1) Access: Improve access to high-quality, locally produced food for low-income residents in Whitman County; (2) education: Enhance community awareness and response to food systems and nutritional issues; and (3) production: Increase local production and delivery of nutritious food, linking the effort to job-skills training and economic development.

The Palouse Food Project began with a grant from the Washington State Higher Education Coordinating Board to WSU's Center for Civic Engagement, which provided funding to develop servicelearning internships related to food security and community gardening. With this funding, WSU students supported and, in many instances, initiated activities at schools and agencies in the community. For example, a local elementary school had just installed a greenhouse and wanted to create a gardening curriculum for their students and establish a lunchtime gardening club. The Community Action Center 
wanted to increase the amount of fresh produce available for their food bank clients by cultivating garden plots at the local community garden. The two community organizations, connected with WSU faculty and students who were coordinated by the WSU Center for Civic Engagement, engaged in a series of "mutually reinforcing activities" (Kania \& Kramer, 2011, p. 38) - gardening with school children and making fresh produce available in area food banks. WSU student interns who had been recruited, trained, and placed by the Center for Civic Engagement initiated, supported, and engaged other students in these efforts to move them forward. These early efforts multiplied quickly. For example, the first-year crop at the community garden plot yielded an overabundance of basil. Instructions for using and cooking with basil, as well as recipes, were quickly written up and given to food bank clients. This led to the involvement of a nutrition class the following year to make available other recipes that call for fresh produce as ingredients. Later on, this led to cooking demonstrations by students, and ultimately the Community Action Center installed a commercial kitchen for preparing and preserving food.

The cross-sector and interdisciplinary coalition sustaining the Palouse Food Project has changed over time, as has its emphasis, from access, education, and production to communication, coordination, and recovery. In 2014, to support a need for coordinating numerous disparate efforts related to food security, the WSU Center for Civic Engagement initiated a three-year AmeriCorps VISTA project focused on the Palouse food initiative. Having a full-time VISTA member dedicated to convening and coordinating groups engaged in fresh-food access and distribution multiplied the impacts of individual efforts. In the first two years of the VISTA project, the Palouse Fresh Food Project collaborated with 16 community organizations to develop service-learning opportunities for over 2,000 students. Since the project began, faculty and students from human development, landscape architecture, education, communication, apparel merchandising and design, sociology, and digital technology have been intimately and productively engaged. Outcomes of these efforts include: a Student Guide to Successful Donation Drives, the Whitman County Fresh Food Donation Guide, the Whitman County Seed Library, a photovoice project on food access, a Mobile Agricultural Center prototype, the design of Mary's Park with edible landscaping, the Tekoa School garden design, unique reusable food pantry grocery bags, and a website for the Pullman Schools food pantries.

Founding community organizations, such as the Community Action Center and the WSU Organic Farm, remain foundational partners and have been joined by several others: Backyard Harvest, Pullman Parks and Recreation, the Pullman Farmers Market, the Pullman Chamber of Commerce, the Whitman County Health Department, and more. The Palouse Food Project is now aligned with two emergent regional food coalitions - the Whitman County Food Coalition and the Palouse-Clearwater Food Coalition - with shared goals of reducing food insecurity on the Palouse through food production, access, and education. By aligning with groups serving the Palouse-Clearwater area, the impact of this project now extends into a four-county area in southeastern Washington and northern Idaho. These alliances have had many positive impacts on food security in the region, recording a 3\% decline in food insecurity in Whitman County since 2015. Joint efforts have resulted in SNAP/EBT food-benefit availability at the Pullman and Moscow (Idaho) Farmer's Markets as well as increased coordination among 14 regional food pantries to get fresh food on the shelves, revitalizing those connections. In addition, a recent focus on food recovery, especially on the WSU Pullman campus, has resulted in the storage of thousands of prepared meals at local food banks, thanks to the commercial kitchen at the Community Action Center and newer partners such as WSU Dining Services. The world's largest pot of chili at the Palouse Lentil Festival has contributed over 2,500 pounds of nutritious chili to this effort since 2016 !

Despite many twists and turns in its complex history, the Palouse Food Project has contributed to changing the landscape of access to fresh food in the community through the collective efforts of many campus and community partners and with the constant but not always prominent leadership of the university's Center for Civic Engagement. Interestingly, over the years, the center has stepped in and out of the role of the "backbone support organization" (Kania \& Kramer, 2011, p. 39). At other times, currently in fact, the Whitman County Community Action Center has taken on that role through the USDA-funded Palouse Tables Project - a thorough assessment of need related to food security - and a recent USDA proposal to fund a mobile pantry to address the food deserts within the county. As an apparent by-product 
of a strong and dedicated coalition, the leadership of the effort can change quite successfully over time, depending on the focus and opportunities that arise.

The Palouse Food Project is a powerful example of a coalition-based approach to addressing a complex or intractable public or social problem. It is a messy and continuous effort, with outcomes that cannot easily be traced to causes. The 3\% decline in food insecurity, as measured by the most recent community needs assessment, cannot be definitively linked to the overall efforts of the Palouse Food Project. However, that this information exists at all is related to a different campus-community coalition effort, led by two other anchor/backbone support organizations (i.e., Pullman Regional Hospital and the Community Action Center), to design and implement a comprehensive needs assessment in 2015. Campus contributions included the work of a doctoral student in sociology who played a significant role in survey development and analysis, as well as the Social and Economic Sciences Research Center (SESRC), which administered the survey.

Using the framework comprising the five conditions for CI success, Palouse Food Project partners clearly pursued a common agenda, targeting hunger in the geographic region. Most member institutions were represented at preexisting social-sector coordinating meetings, simplifying the planning of mutually reinforcing activities by individual partners. WSU's Center for Civic Engagement and the Whitman County Community Action Center moved in and out of the backbone support organization role consistently over the period of the project. These two entities, and the coordinating council, ensured continuous communication among organizations. Throughout its 15-year history, collaborative partners collected and shared data based on the goals and objectives of the Palouse Food Project, employing various evaluation and assessment strategies. Missing from this case, however, is systematic and longitudinal empirical research, necessary to generate evidence of impact, despite the fact that university-based faculty and other researchers participated in coalition activities throughout the period reported here. This, compounded by the inherent difficulty of establishing a causal relationship between Palouse Food Project activities and a statistic like the decline in food insecurity cited earlier, actually highlights the value of CEPs intentionally positioning a university-based unit as the backbone support organization. Universities do have the capacity to design and lead program evaluations and (quasi-)experimental studies to produce the empirical data necessary to demonstrate the impact of collective action on a particular complex issue.

The Palouse Food Project was not consciously initiated as a collective impact initiative. This case does, though, present a valuable opportunity to juxtapose the lived experience of CEPs at work in a community coalition with the conditions for success, thereby bridging next-generation CEP competencies and CI principles of practice. Doing so highlights areas requiring attention in the future. Most notable is the gap between the daily practice of a CEP and the commitment to and capacity for careful empirical study of the work underway in partnership with other scholars. Said another way, this is the gap that the collaborating for equity and justice model, grounded as it is in the current theory and scholarship of community health and wellness practice, seeks to fill. Until all university-based researchers have been successfully socialized into a community-engaged model for their particular area of interest, CEPs will need to lead the way by walking next to these faculty, working to institutionalize engagement and support change to faculty reward systems. Faculty, in the meantime, should be engaged in leading program evaluations and longitudinal research that surfaces inputs, processes, and outcomes over a long term.

\section{Future Directions}

This article has explored collective impact as a coalition-based approach to addressing complex issues in the context of the anchor-institution movement and, more specifically, the emerging role of community engagement professionals in leading that change. How then might the new competency model, as well as the everyday work of CEPs, be informed through this lens of coalition building and collective impact? We offer recommendations related to each in the sections below. 


\section{A Practice-Based, Results-Oriented Framework}

Community and campus colleagues who take the lead on these coalition-based solutions exhibit many of the CEP competencies presented by Dostilio et al. (2017). Several competencies required of CEPs for working with stakeholder groups are similar, suggesting that a case might be made for moving toward a model that integrates competencies at points of intersection. Whereas the CEP competency model identifies six areas of competency, the CEPs and other boundary-spanning partners involved in the Palouse Food Project rely heavily on three skillsets - a change-oriented vision, opportunity and ability to manage, and relationship building. In the interest of making the competency model more succinct, practical, and accessible to community partners unfamiliar with higher education jargon as well as CEPs, we suggest operationalizing in thematic terms the intersecting knowledge, skills, and dispositions of the CEP competencies as three results-oriented activities common in day-to-day practice:

\section{Leading Change}

- Leading Change in Higher Education: reflecting a deep understanding of the role of higher education in a democracy.

Maximizing Impacts

- Institutionalizing Community Engagement: establishing community-campus engagement as integral to the academic mission.

- Administering Community Engagement Programs: effectively managing risks and resources to maximize impacts on campus and in the community.

Developing Partnerships

- Facilitating Student Civic Learning and Development: optimizing student (and alumni) citizenship in a democracy.

- Facilitating Faculty Development and Support: articulating and advancing the scholarship of engagement.

- Cultivating High-Quality Partnerships: creating diverse, responsible, and reliable networks for change.

What follows is a preliminary examination of these thematic areas in the context of the CI model to determine whether there is an opportunity to develop the CEP competency model further in this frame.

Leading change. Campus centers for community engagement and the professionals affiliated with them are essential to providing the continuity and sustainability needed to cultivate the conditions for change. Often, these centers have a role as gathering places and can be "a powerful organizing center for total university engagement" (Kellogg Commission, 1999). In order to realize that potential, CEPs must see themselves as agents of change, implementing strategies to bring people together and organizing for change (Dostilio et al., 2017). Transformational leaders within the collective impact model similarly "possess strong facilitation, management, and convening skills" and are able to create space for others to establish shared meaning and aspirations, work through their differences, and explore the complexity of the problem they have come together to address (Collective Impact Forum, 2016). For many of these reasons, community engagement centers, led by CEPs, can become effective backbone support organizations within a CI approach, appropriate to the needs and stage of development of the cross-sector collaborations.

A collective impact model also serves as a reminder that leadership for change has temporal and spatial context within and across organizations, systems, and sectors. Institutional and community contexts are critical to the work of community-campus engagement for understanding complex problems, devising strategies and methods, and providing collaborative leadership. Additionally, contexts must be recognized as dynamic so that the work may evolve accordingly (Kowal, 2017). Context is also considered essential to a CI approach whereby developing an initiative to fit the local context allows a coalition to "honor, build on, and/or align with existing work" and pursue "strategies that are most relevant to local needs" (Collective Impact Forum, 2016). The Palouse Food Project was initiated by an organization, the campus civic 
engagement center, with a 10,000-foot contextual view of the community-knowledge of multiple disparate efforts that were not systematically connected. That unique perspective, combined with opportunity and resources, provided the impetus and support for the project.

Many of the complex problems that bring coalitions together in a collective impact or community engagement frame have a root cause of social inequality - particularly social problems with many layers masking systemic social-justice issues such as food security. In the field of community engagement, there is a long history of applying a social-justice lens and, more recently, an intersectional approach to the work (Mitchell, 2017). According to Mitchell (2017), "promoting social justice through community engagement work creates space for coalition building that enacts intersectionality" (p. 42). There is a collective interest in change that moves the needle or bends the arc toward justice, as reflected in the competency model's critical commitments to social change and addressing power differentials. In the CI approach, the prioritization of equity is the first principle of practice for collaborative initiatives. It is considered fundamental to the work to redress systems, practices, and other barriers that work against "equitable outcomes for all populations" (Collective Impact Forum, 2016). One of the main findings of the ORS/SPI study (2018) indicates that initiatives with a strong equity focus showed promise in equity outcomesencouraging news for all those engaged in social-change coalition work.

Maximizing impacts. Ward (1996) described universities as consisting of "loosely coupled" (Weick, 1976, as cited in Ward, 1996) functional areas, connected but distinct. One goal of institutionalizing community engagement is unifying these loosely coupled structures to advance university goals related to its public purpose (Welch \& Saltmarsh, 2013) and thereby maximize the impact of institutional and individual efforts. Collective impact emerged as a platform for distinct organizations to work together for a larger purpose that involves system-level strategies and, ultimately, systemic change. Similarly, in community engagement, CEPs work to implement institutional strategies that transcend departmental and divisional boundaries, advancing institutionalization.

Competencies identified in the community engagement literature related to institutionalization and administration appear comparable to counterparts in the CI literature. Such competencies include, for example, ability to navigate the political environment of the institution/community; cultivating and managing relationships across stakeholders/sectors; use of shared metrics and data to assess outcomes; accessing unique funding opportunities; and communication and marketing skills. Additionally, administration of centers for community engagement and their programs calls for knowledge of organizational theory, the ability to organize, awareness and management of risk, and the ability to create and manage multiple sources of funding, all of which are needed for building coalitions and creating the conditions for change. Similarly, collective impact looks to a backbone support organization to provide this administrative support for change initiatives.

In the case of the Palouse Food Project, the Center for Civic Engagement had access to unique grant opportunities that advanced the overall effort through a coordinated, coalition-based approach to addressing food security in the region. The inherent stability of the center as an institutional resource provides the continuity and level of support needed to address a complex problem.

Developing partnerships. CEPs must be equipped with the knowledge, abilities, and dispositions to effectively engage faculty, students, and community organizations, individually by building relationships and collectively by building bridges. The complexities and distinct nature of each of these groups have been well documented by empirical research in the community engagement literature and may now provide an opportunity to shift slightly the focus from stakeholder groups to a more collective framework.

Collective impact calls for the participation of myriad actors from all sectors relevant to an issue at hand, including those whose lived experience is affected by the problem. Though the leadership must be adaptable to the different voices and situations of the partners in the group, and foster a respectful environment, the emphasis is on the initiative, the outcomes, and the perspectives of the participants rather than on their individual needs. Collective impact first calls for meaningful engagement by cross-sector partners in co-creating: a shared understanding of a problem, an agenda to address that problem, and the implementation of a systemic solution. 
In the case of the Palouse Food Project, with a complex public problem like food security in the community, it was important to find a place to start. Coalition conversations yielded many intersecting issues and potential solutions. A strategy emerged to take just three objectives at a time to focus the coalition's efforts. Initially, three areas of focus were perceived to be most urgent: access, education, and production, essentially connecting the community to more fresh food. Later, as many efforts were underway but disconnected, these focal areas shifted to communication, coordination, and recovery. At all times, however, the vision of reducing food insecurity was paramount.

Community-campus partnerships are central to the work of the CEP, and the literature informing the work is robust (Martin \& Crossland, 2017). Key skills and abilities of CEPs suggested by this literature include communication, inclusion, organization, conflict resolution, partnership management, and democratic collaboration. Brokering community-campus partnerships - as connectors, moderators, intermediaries - is a key role of CEPs that serves faculty, students, and the institution (Weerts \& Sandmann, 2010). Additionally, critical commitments of CEPs include affirming interdependence (an important anchor-institution value) and creating space to make connections and cultivate authentic relationships (also integral to the CI model). The leadership style of the CEP is also a factor in convening, facilitating, and leading campus-community relationships. In addition to enhancing partnerships, CEPs need to influence and broker campus (i.e., faculty, student, administrator) perspectives of community, and vice versa, helping each to recognize the importance of diverse perspectives and experiences to a democratic collaboration.

\section{Critical Commitments for Future Practice}

Building upon the earlier case analysis of the Palouse Food Project vis-à-vis collective impact practice, we offer several critical commitments that community engagement professionals must embrace and enact in their everyday practice.

1. Complex public problems can only be resolved through the collective effort of a coalition thoughtfully populated by community and campus participants. Maintaining this critical commitment will spark the development or refinement of knowledge and skills that makes coalition building and CI a more central aspect and expectation for CEPs in the future.

2. Efforts toward institutionalization of boundary-spanning functions are critical as a foundation for university-based actors' contributions to complex problem solving. Whether referred to as a backbone support organization or an essential part of an anchor institution, the boundary-spanning units and CEPs themselves are well positioned to take this work into the next generation of democratic problem solving at the local level. The challenge in many cases will be institutional support for work that many still regard as peripheral to the primary work of the institution.

3. The pursuit of equity and justice in communities will necessitate systemic change through the work of coalitions. Justice, equity, diversity, and inclusion (or JEDI) must be at the core of all community engagement activity. The scholarly disagreement between CI practitioners (e.g., White et al., 2019) and scholar-practitioners in public health and community practice (e.g., Kegler et al., 2019; Wolff, 2016; Wolff et al., 2017) have elevated equity and social justice as necessary goals for any collaborative approach to problem solving. Surprisingly, neither justice nor equity appears in the CEP competency model; instead, the authors speak only of injustice. The value of the CI principles of practice is in the extent to which the statements make plain what right action looks like in that model. The same is necessary in articulating CEP competencies. Another potential contribution from collective-impact work are the notions of systems thinking, systems strategies, and systemic change. The pragmatic nature of this frame can be grounding, especially in an academic environment steeped in a world of ideas. The Palouse Food Project example demonstrates the need to think in these terms of connectedness and interdependence in order to achieve the incremental outcomes that lead to change. Incorporating competency in systems thinking may be a useful tool for CEPs in the future.

4. Lasting change is co-created through equitable and socially just partnerships operating with a commitment to community voice and community authority. CEPs should consider a slight 
paradigm shift toward equity and inclusion of cross-sector partners, across campus and communities. Traditional thinking about, and consideration of, the distinctiveness of stakeholder groups - students, faculty, and community partners - does not advance an equitable frame, with at least two thirds of attention paid to campus stakeholders (more if one considers institutional administrators as a separate stakeholder group). A coalition frame places the emphasis on cocreating change through equitable partnerships.

CEPs play an important role in promoting transformational change and creating the engaged institution (Hübler \& Quan, 2017). Convening and facilitating groups of campus and community colleagues is a natural enterprise of the CEP. Though it is easy to get caught in a short-term mindset - the impending grant deadline or upcoming event - truly moving the needle, by definition, requires critical thought and sustained, integrated action by multiple partners. The collective impact model, built around the idea of problem complexity and the necessity of cross-sector collaborators invested in a process to achieve outcomes, is worth considering as a complement to next-generation community engagement and the CEP competency model.

\section{Notes}

1. We periodically use first-person language here and in the following pages to foreground our own practice as boundary spanners and also to point toward that of our colleagues. Like White, Wolff, and others cited herein, we bring a commitment to justice and equity to what, how, and why we do this work with community partners to address complex public problems.

2. For example, see http://wisconsinidea.wisc.edu/ for current examples of University of Wisconsin faculty enhancing the quality of life, educating young and old, advancing health and medicine, and building Wisconsin's economy.

\section{References}

Bartha, M., Carney, M., Gale, S., Goodhue, E., \& Howard, A. (2014). This bridge called my job: Translating, re-valuing, and leveraging intermediary administrative work. Public: A Journal of Imagining America: Hybrid, Evolving, and Integrative Career Paths, 2(2). Retrieved from $\mathrm{http}$ //public.imaginingamerica.org/blog/article/this-bridge-called-my-job-translating-re-valuingand-leveraging-intermediary-administrative-work

Boyer, E. L. (1990). Scholarship reconsidered: Priorities of the professoriate. Princeton, NJ: Carnegie Foundation for the Advancement of Teaching.

Boyer, E. L. (1996). The scholarship of engagement. Journal of Public Service and Outreach, 1(1), 1120.

Boyte, H., \& Fretz, E. (2010). Civic professionalism. Journal of Higher Education Outreach and Engagement, 14(2), 67-90.

Cantor, N., Englot, P., \& Higgins, M. (2013). Making the work of anchor institutions stick: Building coalitions and collective expertise. Journal of Higher Education Outreach and Engagement, 17(3), 17-46.

Collective Impact Forum. (2016). Collective impact principles of practice. Retrieved from https://www.collectiveimpactforum.org/resources/collective-impact-principles-practice

Dostilio, L. D. (Ed.). (2017a). The community engagement professional in higher education: A competency model for an emerging field [Adobe Digital Editions version].

Dostilio, L. D. (2017b). Planning a path forward: Identifying the knowledge, skill, and dispositions of second generation community engagement professionals. In L. D. Dostilio (Ed.), The community engagement professional in higher education: A competency model for an emerging field [Adobe Digital Editions version]. 
Dostilio, L. D., Benenson, J., Chamberlin, S., Crossland, S., Farmer-Hanson, A., \& Hernandez, K. (2017). Preliminary competency model for community engagement professionals. In L. D. Dostilio (Ed.), The community engagement professional in higher education: A competency model for an emerging field [Adobe Digital Editions version].

Dostilio, L. D., \& McReynolds, M. (2015). Community engagement professionals in the circle of servicelearning and the greater civic enterprise. Michigan Journal of Community Service Learning, $18(1), 113-116$.

Dostilio, L. D., \& Perry, L. G., (2017). An explanation of community engagement professionals as professionals and leaders. In L. D. Dostilio (Ed.), The community engagement professional in higher education: A competency model for an emerging field [Adobe Digital Editions version].

Friedman, T. L. (2018, June 26). Why are so many political parties blowing up? (Part 1). Retrieved from https://www.nytimes.com/2018/06/26/opinion/political-parties-climate.html

Garber, M., \& Adams, K. R. (2017). Achieving collective impact: Reflections on ten years of the University of Georgia Archway Partnership. Journal of Higher Education Outreach and Engagement, 21(1), 6-29.

Heifetz, R., Kania, J. V., \& Kramer, M. (2004). Leading boldly. Stanford Social Innovation Review, 2(3). Retrieved from: https://ssir.org/articles/entry/leading_boldly

Hodges, R. A., \& Dubb, S. (2012). The road half traveled: University engagement at a crossroads. East Lansing, MI: Michigan State University Press.

Hübler, R., \& Quan, M. (2017). Envisioning, leading, and enacting institutional change for the public good: The role of community engagement professionals. In L. D. Dostilio (Ed.), The community engagement professional in higher education: A competency model for an emerging field [Adobe Digital Editions version].

Longo, N. V., Kiesa, A., \& Battistoni, R. (2016). The future of the academy with students as colleagues. In M. A. Post, E. Ward, N. V. Longo, \& J. Saltmarsh (Eds.), Publicly engaged scholars: Next generation engagement and the future of higher education (pp. 197-213). Sterling, VA: Stylus.

Kania, J., Hanleybrown, F., \& Juster, J. S. (2014). Essential mindset shifts for collective impact. Stanford Social Innovation Review [Supplement sponsored by Collective Impact Forum], 12(4), S2-S5.

Kania, J., \& Kramer M. (2011). Collective impact. Stanford Social Innovation Review, 9(1). Retrieved from http://www.ssireview.org/articles/entry/collective_impact\#comments

Kania, J., \& Kramer, M. (2013). Embracing emergence: How collective impact addresses complexity. Stanford Social Innovation Review. Retrieved from https://ssir.org/articles/entry/social_progress_through_collective_impact

Kegler, M. C., Wolff, T., Christens, T., Butterfoss, F. D., Francisco, V. T., \& Orleans, T. (2019). Strengthening our collaborative approaches for advancing equity and justice. Health Education and Behavior, 46(1S), 5S-8S.

Kellogg Commission on the Future of State and Land-Grant Universities. (1999) Returning to our roots: The engaged institution. Washington, DC: National Association of State Universities and LandGrant Colleges.

Kowal, M. M. (2017). Evolution of a profession: A review of The community engagement professional in higher education: A competency model for an emerging field. International Journal of Research on Service-Learning and Community Engagement, 5(1), 181-183.

Martin, L. \& Crossland, S. (2017). High quality community-campus partnerships: Approaches and competencies. In L. D. Dostilio (Ed.), The community engagement professional in higher education: A competency model for an emerging field [Adobe Digital Editions version].

McGuinness, T., \& Slaughter, A.-M. (2019). The new practice of public problem solving. Stanford Social Innovation Review. Retrieved from https://ssir.org/articles/entry/ the_new_practice_of_public_problem_solving

Mitchell, T. D. (2017). Teaching community on and off campus: An intersectional approach to community engagement. New Directions for Student Services, 2017(157), 35-44. 
Moore, T. L. (2014). Community-university engagement: A process for building democratic communities. ASHE Higher Education Report, 40(2). San Francisco, CA: John Wiley.

Moore, T. L., \& Ward, K. A. (2010). Institutionalizing faculty engagement through research, teaching, and service at research universities. Michigan Journal of Community Service Learning, 17(1), 44-58.

Orphan, C., Solodukhin, L. D., \& Romero, D. (2018). Fostering collective impact: Measuring and advancing higher education's contributions to civic health and equity in Colorado. International Journal of Research on Service-Learning and Community Engagement, 6(1), Art. 5.

ORS Impact \& Spark Policy Institute. (2018). When collective impact has an impact. Retrieved from http://orsimpact.com/directory/ci-study-report.htm

Phills, J. A., Deiglmeier, K., \& Miller, D. T. (2007). Rediscovering social innovation. Stanford Social Innovation Review, 6(4), 34-43.

Post, M. A., Ward, E., Longo, N. V., \& Saltmarsh, J. (2016). Introducing next-generation engagement. In M. A. Post, E. Ward, N. V. Longo, \& J. Saltmarsh (Eds.), Publicly engaged scholars: Next generation engagement and the future of higher education. Sterling, VA: Stylus.

Schmitz, P. (2012, November 27). The real challenge for collective impact. Retrieved from https://www.huffingtonpost.com/paul-schmitz/collective-impact_b_1920466.html

Shannon, J., \& Wang, T. R. (2010). A model for university-community engagement: Continuing educations role as convener. Journal of Continuing Higher Education, 58(2), 108-112.

Ward, K. (1996). Service-learning and student volunteerism: Reflections on institutional commitment. Michigan Journal of Community Service Learning, 3(1), 55-65.

Ward, K. A., \& Moore, T. L. (2010). Defining the "engagement" in the scholarship of engagement. In H. E. Fitzgerald, C. Burack, \& S. D. Seifer (Eds.), Handbook of engaged scholarship: Contemporary landscapes, future directions: Volume I: Institutional change (pp. 39-54). East Lansing, MI: Michigan State University Press.

Weerts, D. J., \& Sandmann, L. R. (2010). Community engagement and boundary spanning roles at research universities. Journal of Higher Education, 81(6), 702-727.

Welch, M., \& Saltmarsh, J. (2013). Current practice and infrastructures for campus centers of community engagement. Journal of Higher Education Outreach and Engagement, 17(4), 25-56. Retrieved from https://openjournals.libs.uga.edu/jheoe/article/view/1067/1066

Whitchurch, C. (2009). The rise of the blended professional in higher education: A comparison between the United Kingdom, Australia and the United States. Higher Education, 58(3), 407-418. https://doi.org/10.1007/s10734-009-9202-4

White, B. P. (2009). Navigating power dynamics between institutions and their communities. Dayton, $\mathrm{OH}$ : Kettering Foundation. Retrieved from https://www.kettering.org/catalog/ product/navigating-power-dynamics-between-institutions-and-their-communities

White, B. P. (2010). Power, privilege, and the public: Dynamics of community-university collaboration. In N. Thomas (Ed.), New directions for higher education (No. 152): Education for deliberative democracy (pp. 67-74). San Francisco, CA: Wiley.

White, B. P. (2012). Confronting the careless university. eJournal of Public Affairs, 1(2). Retrieved from $\mathrm{http}: / / \mathrm{www}$.ejournalofpublicaffairs.org/wp-content/uploads/2018/07/EJOPA1.2.pdf

White, B. P. (2018). Collective impact from the inside out. Connections: An Annual Journal from the Kettering Foundation. Retrieved from https://www.kettering.org/sites/default/ files/periodical-article/connections_18_white.pdf

White, B. P., Blatz, J., \& Joseph, M. L. (2019). Elevating community authority in collective impact. Stanford Social Innovation Review, 17(1), 48-55.

Williams, P. (2002). The competent boundary spanner. Public Administration, 80(1), 103-124.

Wolff, T. (2016). Ten places where collective impact gets it wrong. Global Journal of Community Psychology Practice, 7(1), 1-11.

Wolff, T., Minkler, M., Wolfe, S. M., Berkowitz, B., Bowen, L., Butterfoss, F. D., ... Lee, K. S. (2017). Collaborating for equity and justice: Moving beyond collective impact. Nonprofit Quarterly. 
Retrieved from https://nonprofitquarterly .org/collaborating-equity-justice-moving-beyondcollective-impact

\begin{abstract}
About the Authors
Melanie Brown is former Director of the Center for Civic Engagement at Washington State University.

Tami L. Moore is Associate Professor of Higher Education and Student Affairs as well as Co-director of the Center for Public Life at Oklahoma State University - Tulsa.

Correspondence concerning this article should be addressed to Tami L. Moore at tami.moore@,okstate.edu.
\end{abstract}

